\title{
Chronic granulomatous disease (CGD) presenting as quotidian
} fever

\author{
K Moenkemoeller*1, R Cremer ${ }^{1}$, J Roesler ${ }^{2}$, A Schulz ${ }^{3}$, M Weiss ${ }^{1}$ and \\ C Schuetz ${ }^{3}$
}

Address: ${ }^{1}$ Kinderkrankenhaus, Kliniken der Stadt Koeln gGmbH, Koeln, Germany, ${ }^{2}$ Klinik und Poliklinik für Kinder- und Jugendmedizin, Universitätsklinikum Carl Gustav Carus, Dresden, Germany and ${ }^{3}$ Klinik für Kinder- und Jugendmedizin, Universitätsklinikum Ulm, Ulm, Germany

* Corresponding author

from I5 ${ }^{\text {th }}$ Paediatric Rheumatology European Society (PreS) Congress

London, UK. 14-17 September 2008

Published: 15 September 2008

Pediatric Rheumatology 2008, 6(Suppl I):P203 doi:10.1 I86/I546-0096-6-SI-P203

This abstract is available from: http://www.ped-rheum.com/content/6/SI/P203

(c) 2008 Moenkemoeller et al; licensee BioMed Central Ltd.

\section{Background}

Quotidian fever of unknown origin involves a broad differential diagnosis and challenges therapeutic decision making. We identified CGD in a five year old Turkish boy with systemic inflammation mimicking systemic onset JIA (SOJIA).

\section{Clinical case}

The patient presented with 7 days of spiking fever not responding to oral antibiotics, arthralgias and a maculous rash. Laboratory results showed leukocytosis, thrombocytosis, CrP of $240 \mathrm{mg} / \mathrm{l}$, ESR $100 \mathrm{~mm}$. The symptoms persisted under intravenous antibiotic treatment. Focus work-up gave no evidence of an infectious origin, malignancy, IBD, vasculitis, connective tissue disease or periodic fever syndrome. Due to suspicion of incomplete SOJIA a steroid pulse was given. Disease activity responded promptly, consequently methotrexate was added.

After steroid reduction fever and arthralgias recurred and inflammation increased. Physical and radiological examinations and echocardiography were normal. Another steroid pulse was successful and Ciclosporine was added. Again systemic inflammation appeared with decreasing steroids. Thorax x-ray showed interstitial infiltrates. CT identified a ground-glass pattern, a circular pleural lesion and a small hypodense hepatic lesion. Those two abscesses led us to perform granulocyte function tests:
Dihydrorhodamine-testing showed absent NADPH-oxidase activity. Aspergillus fumigatus was cultivated following pulmonary lavage.

The child responded well to antibiotic and anti-fungal treatment. Stem cell transplantation is being discussed as a curative treatment.

\section{Conclusion}

SOJIA as one cause of systemic inflammation is an exclusion disorder. The incidental finding of abscesses in our case led to CGD. This emphasizes the need for repeated diagnostic approaches in patients with unexplained fever attacks. 